Available online on 15.5.2018 at http://ujpr.org
Universal Journal of Pharmaceutical Research
An International Peer Reviewed Journal
Open access to Pharmaceutical research

\title{
IDENTIFYING AND PRIORITIZING FACTORS EFFECTIVE ON HOSPITAL SERVICES QUALITY FROM THE PATIENT ATTENDANTS VIEW USING FUZZY AHP TECHNIQUE IN 2017 \\ Leila Samarmand $^{1}\left(\mathbb{D}\right.$, Shaghayegh Vahdat $^{2}{ }^{\circ}$, Somayeh Hessam ${ }^{2}(\mathbb{C}$ \\ ${ }^{I}$ Department of Healthcare Management, Marvdasht Branch, Islamic Azad University, Marvdasht, Iran. ${ }^{2}$ Department of Health Services Administration, South Tehran branch, Islamic Azad University, Tehran, Iran.
}

\section{ABSTRACT}

Objective: Hospitals play a very significant role in providing healthcare services and supplying the society's health. So, the method of evaluating hospitals services quality has a special importance. The aim of this study is to identify and prioritize factors effective on hospitals services quality from view of patients' attendants in Zeinab Hospital of Shiraz City. This study is applied in respect of objective and in respect of method, it is descriptive- applied and qualitative method has been used. The statistical population of this study is patient's attendants referring to Zeinab Hospital in 2017.

Methods: For prioritizing indicators, fuzzy AHP questionnaire was used. For data analysis, Excel software was used. The study results indicate that among indicators effective on hospital services quality from patient attendants view, the access indicator with weight of 0.3373 and the general services indicator with weight of 0.3327 were located in the first and second priority respectively and the environmental indicator with weight of 0.1629 was identified as the least significant indicator respectively. Also, among subcategories of access component, sub-branches of access to medical team with weight of 0.4003 and access to round the clock services with the weight of 0.3304 were in the first and second rank respectively.

Results: Among subcategories of general services indicator, subcategories of low cost with weight of 0.3623 and hospital responding to patients needs with weight of 0.3304 were the most effective sub-branches. Among subcategories of communicational component, personnel liability with weight of 0.5836 and sub-branch of personnel correct contact with patients with weight of 0.2773 were in the first and second priority respectively and finally relating to environmental component two indicators of services and facilities being up-to-date with weight of 0.4140 and having parking were in the first and second priority. Conclusion: Decision makers and managers of Zeinab Hospital should more notice the indicators of access and general services due to their significance and impact on hospital services as one of Zeinab Hospital operational approaches for promoting and improving services quality.

Keywords: Fuzzy AHP, hospital services quality, patient attendants, Zeinab hospital.

Article Info: Received 2 March 2018; Revised 13 April; Accepted 9 May, Available online 15 May 2018

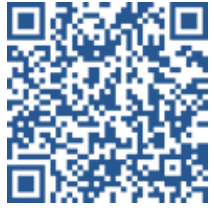

Cite this article-

Samarmand L, Vahdat S, Hessam S. Identifying and prioritizing factors effective on hospital services quality from the patient attendants view using Fuzzy AHP technique in 2017. Universal Journal of Pharmaceutical Research 2018; 3(2): 19-26.

DOI: https://doi.org/10.22270/ujpr.v3i2.135

Address for Correspondence

Shaghayegh Vahdat, Assistant Professor, Department of Health Services Administration, South Tehran branch, Islamic Azad University, Tehran, Iran. E-mail: sha_vahdat@yahoo.com

\section{INTRODUCTION}

The main mission of hospitals is to supply high-quality care for patients and meeting their needs and expectations and performing this requires establishment of quality in these centers. Today, the main problem of policy makers of health domain in world level is to evaluate and identify requirements and quality of people access to optimal health services. The structure of healthcare services sector and competing observations is shifting towards a direction in which patients play the main role in defining quality.
Therefore, patients and their family should be known as consumers of healthcare services and their needs and expectations should be considered in developing products and healthcare services as main factor. Regarding the patients' needs in providing quality evaluation causes healthcare services to respond people needs. Various factors are effective on hospital services quality. According to Zarei et al., ${ }^{2}$ factors like sensible factors (polished and ordered appearance of personnel, personnel neat and clean environment, new and update hospital equipment and fitness of physical environment and signs and guides), trust dimension (providing 
services according to commitments, personnel interest to solve the patients problems, accurate performance of services in the first turn), responding dimension (notifying the patient the time of performing various services, the personnel tendency to help patients, personnel accessibility when required), warranty dimension (creating trust and confidence sense in patients, sense of security and peace during communication with personnel and responding patient questions), sympathy dimension (individual attention to each patient, hospital round the clock services accessibility and personnel heartfelt interest to patients) are effective on hospital services quality. Ross et al., believes that food, personnel behavior, environment cleanness, reception process and diagnostic services are effective on nurses' healthcare services ${ }^{5}$. Maharmeh et al., ${ }^{6}$ introduces access to modern medical equipment, visiting system, expectation time, suitable expectation room and personnel behavior are among factors effective on hospital services quality.

Table 1: Verbal- qualitative space for evaluating factors and determining their significance degrees.

\begin{tabular}{cc}
\hline Verbal rate & Verbal word \\
\hline OU & Highly significant \\
VH & Very high \\
H & high \\
M & Medium \\
L & Low \\
VL & Very low \\
N & Insignificant \\
\hline
\end{tabular}

The results obtained from a previous study shows that there is a direct relation between factors like personnel, modern and cleanness of hospital environment on hospital services quality from patients view ${ }^{5}$. This means that by increasing of these factors, the quality of hospital services is increased. Azizi et al., ${ }^{3}$ showed that components of professional competence, treatment costs, personnel behavior and physicians relation with patients have the greatest impact on hospitals services quality. Liona et al., ${ }^{8}$ considered factors like establishing relation with patient and providing consultation, the patient economic crises, disruption and personnel behavior as the most important factors effective of hospital services quality. But it should be noted that regarding the restriction of resources and facilities of the organizations and also necessity of supplying customers' satisfaction, the organizations should identify factors effective on hospital services quality from point of view of patients and their attendants and by identifying the most important factors, perform required actions for improving the services quality. But attention to the customers' satisfaction in healthcare services due to nature of these services and their customers has some differences with other services. Also, factors like increasing competition among treatment institutions for improving quality, existence of mistakes and invalidity of performance reports of healthcare centers, environmental factors influencing healthcare system such as demographic changes, political environment, social perception of health quality and so on which cause considerable changes in this system all are factors that cause increasing of significance of noticing services quality in healthcare centers and turning of researchers to identifying factor effective on quality of healthcare services. Regarding the significance of the topic and emphasis of Ministry of Health, Treatment and Medical Training on patients' satisfaction, this study has identified and prioritized factors effective on hospital services quality from patients attendants view using fuzzy AHP technique.

\section{METHODS}

The present study was of descriptive- applied type. It's being applied was for this reason that the results obtained from it could be used by managers, decision makers and programmers of hospitals. The statistical population of this study includes a number of patients attendants informed of hospital services quality and the number of samples was 20 persons who were selected with purposeful sampling method. The tool used for collecting data in this study included interview, questionnaire, table, databases and computer networks. The required data was collected through questionnaire and interviewing with attendants of patients referring to Zeinab Hospital. All ethical issues in performing the study were considered. These cases include receiving instruction letter from Islamic Azad University, Marvdasht Branch, providing it to management and guard of Zeinab Hospital, assuring the patients' attendants of confidentiality of information and also providing required explanations to people participating in the interview for getting familiar with the study aim. Also, all people selected for the interview and filling the questionnaires were quite free in giving information and in case of dissatisfaction, the individual was omitted from the survey and another person was replaced. Observing honesty was considered in data analysis.

In this study, multivariate decision making model of fuzzy AHP was used for ranking the components relating to the study. The process of fuzzy hierarchical analysis is a powerful method for solving the complex multivariate decision making problems which has been introduced by Saati. When in decision making, we face several options and indicators, this approach could be useful. Though experts use their mental competences and abilities for doing comparisons, yet this point should be noted that the traditional hierarchical analysis process doesn't have the possibility to completely reflect human thinking style. In other words, using fuzzy sets has more consistency with human ambiguous verbal explanations and so it is better to utilize fuzzy numbers for long-term predicting and decision making in the real world. Several methods have been suggested for fuzzy hierarchical analysis process. Among the first attempts for making AHP fuzzy, we may point to the method provided by two Dutch researchers called Larhoon and Pedrikez which is based on logarithmic least squares method. But the number of calculations and complexity of stages caused it not to be used so much. Therefore, simpler methods for utilizing fuzzy AHP were developed that 
we may point to Barkley method. In this method, trapezoidal fuzzy numbers have been used and also for computing weights, geometric average has been used and finally, Chang provided a new method for applying fuzzy AHP called developmental analysis method in which a class of analytical instruments will be used.

Fuzzy logic is not a multivariate decision making technique but it is an equivalent approach for quantifying rates.

Fuzzy logic is in fact a way for breaking this scientific order coincident with divalent thinking. In other words, fuzzy logic is a way for scientific thinking with human method more than scientific logic era. In all multivariate decision making approaches based on experts views, the verbal phrases should be turned to quantitative form. With traditional methods of multivariate analysis, quantitative range with finite numbers is used. Other computations are also performed based on the technique fundamental principles. With this difference that the algebraic operation is done with fuzzy numbers algebraic operation. In respect of historical background, accurate and bivalent thinking are attributed to Aristotle in Greek and in Aristotle thinking, no moderate state is visualized, while fuzzy thinking refers to Buddhism in Indi and Before Christ Birth and two centuries before Aristotle, that several centuries after him Polish Lukasei in 1930 published fuzzy three-value thinking under the title of modern fuzzy sets. Today, some consider fuzzy approach as principle of dynamic and peaceful life in the modern world and on the other hand, it is known as a new ideology in the area of mathematics and modern sciences and consistency with human nature and it has various usages in human life.

\section{RESULTS AND DISCUSSION}

\section{Fuzzy screening of indicators}

Multi-indicator decision making problems require evaluation and determination of studied topics and phenomena functional value which requires screening, identifying and selecting a significant and key indicator of evaluation. Screening problems with great subsets (X) begin with possible options. The process of selecting a subset of "a" from " $\mathrm{x}$ " is named screening process. Implementing this technique just requires providing verbal priority information with ordinal scale. This characteristic allows decision making team members to provide their knowledge and information about their satisfaction rate on criteria or options of decision in the form of verbal variables like highly significant, very significant, significant, fairly significant, a little insignificant, very insignificant and insignificant and the ability of performing the operation on inaccurate verbal priorities allows them to use resources with minimum information relating to investigated topic. In other words, any decision maker states his opinion and view about significance degrees of every criterion. This evaluation is done in the form of elements of qualitative scale defined in the Table 1.

About 19 indicators were considered for the present study that finally, 13 indicators were known highly significant from viewpoint of 20 experts, which include indicators one, two, three, five, eight, nine, ten, twelve, fourteen, fifteen, seventeen, eighteen and nineteen. According to experts view, these indicators were located in four categories of access, general services, environmental and communicational. Access indicator shows access to hospital services provided by the hospital for patients like access to medical team, access to round the clock services and access to ambulance services. The indicator of general services of this dimension of services quality shows non-treatment services provided by the hospital for patients, like low cost, method of responding the patients' needs, having insurance and less beds in each room. The communicational indicator shows the relation between services provider and use that includes subcategories of personnel liability, personnel correct contact with patients and personnel honesty and finally environmental indicator shows environmental features and facilities which constitute the patient perception of services and includes facilities and equipment being up-to-date, food quality and having parking lot.

Computing the weight if components effective on hospital services quality

The following matrix is obtained from integrating views of 20 experts in Shiraz Zeinab Hospital which are incorporated:

Regarding the results of Table 4, among indicators effective on hospital services quality, the access indicator with weight of 0.3373 is in the first rank and the environmental indicator with weight of 0.1620 in the fourth rank.

\section{Computing the weight of subcategories of access} indicator

In this section, the weight of subscales of access indicator will be computed:

Regarding the results of Table 6, among subscales of access indicator, the subscale of access to medical team with weight of 0.4003 is in the first priority and the subscale of access to ambulance services with weight of 0.2830 is in the third priority. Computing weight of subcategories of general services in general services

In this section, the indicator of general services will be computed: Table 8 indicates that among subscales of component of general services, low cost with weight of 0.3623 was located in the first priority and method of responding patients' needs with weight of 0.1277 is in the fourth priority

Computing the weight of subcomponents of communicational indicator

In this section, the weight of subcomponents of communicational indicator will be computed. Regarding Table 10 among subcategories of communicational indicator, subscale of personnel liability with weight of 0.5836 is in the first priority and subscale of personnel honesty with weight of 0.1391 in the third rank.

Computing weight of subscales of environmental indicator

In this section, the weight of subscales of environmental indicator will be calculated. Regarding the results of Table 12, among subscales of environmental indicator, the subscale of facilities and equipment being updated with the weight of 0.4140 is 
in the first rank and the subscale of having parking lot with the weight of 0.2013 in the third rank.

\section{CONCLUSION}

This study has investigated the impact of communicational factors impact (personnel liability, personnel honesty and correct contact of personnel with the patients), access factors ( access to medical team, access to round the clock services and access to ambulance), factors if general services (low cost, less beds in each room, method of responding hospitals to the patients' needs and having insurance) and environmental factors (having parking, food quality and facilities and equipment being up-to-date) on hospital services quality from viewpoint of patients attendants in Zeinab hospital.

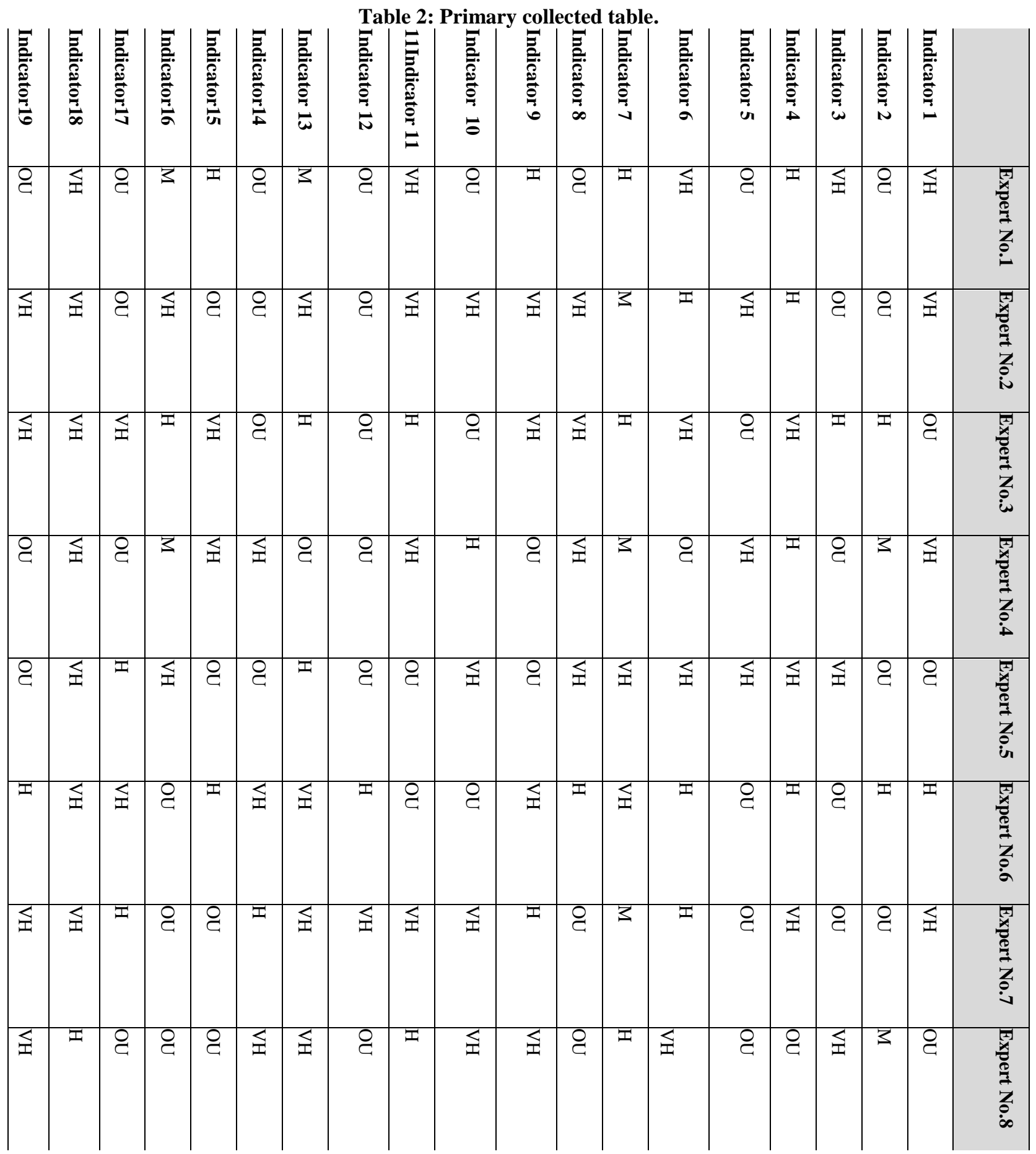




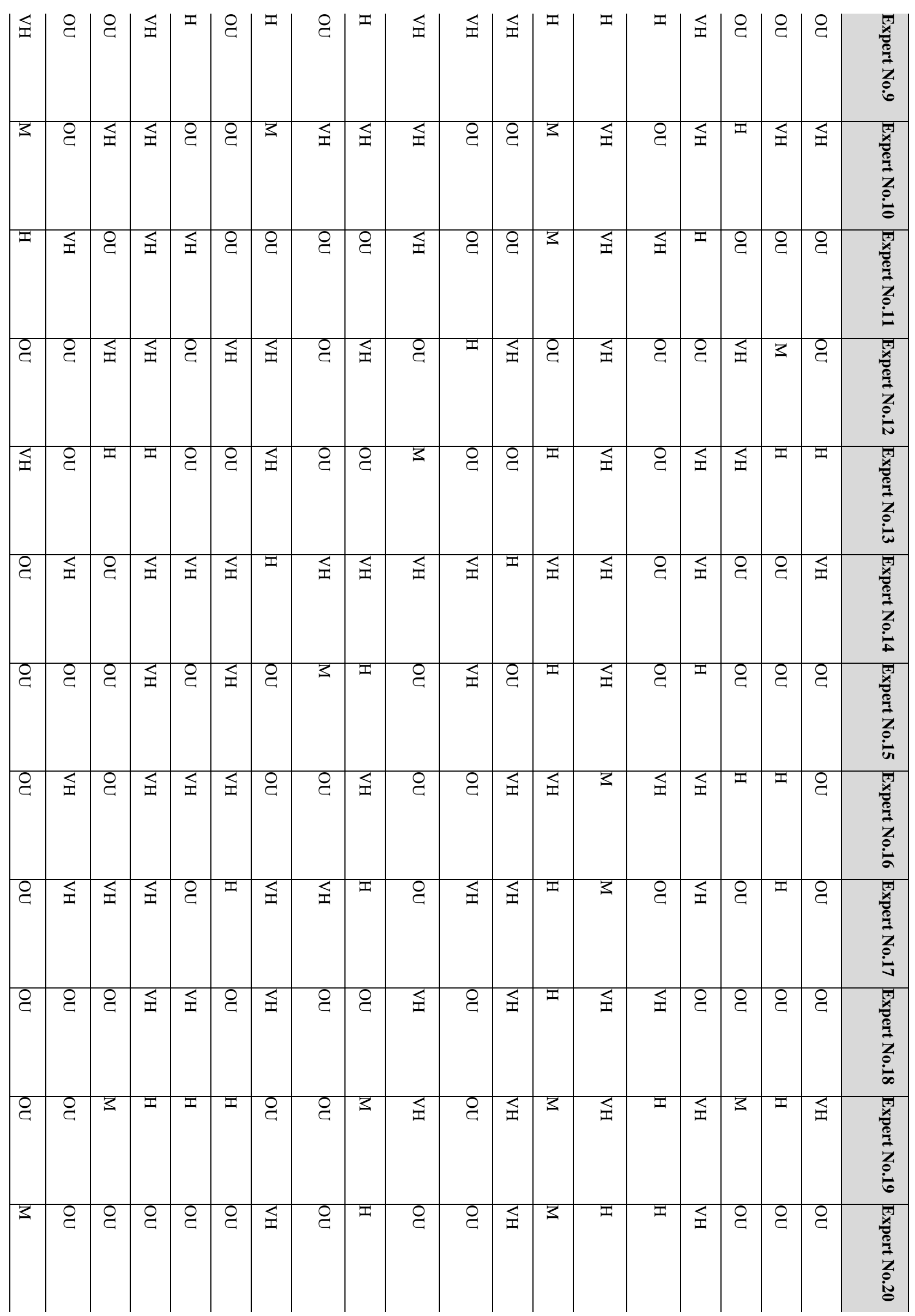


Table 3: Definite reciprocal geometric average of triangular fuzzy numbers for criteria.

\begin{tabular}{lllll}
\hline Item & Criterion & $\begin{array}{l}\text { First fuzzy } \\
\text { number }\end{array}$ & $\begin{array}{l}\text { Second fuzzy } \\
\text { number }\end{array}$ & $\begin{array}{l}\text { Third fuzzy } \\
\text { number }\end{array}$ \\
\hline 1 & Access & 0.229 & 2.2978 & 5.0454 \\
2 & General services & 0.5774 & 1.2893 & 5.1962 \\
3 & Communicational & 0.2296 & 0.8001 & 2.59 \\
4 & Environmental & 0.1925 & 0.4219 & 2.59 \\
Total rates Z & & 1.2223 & 4.8091 & 15.4216 \\
Z reversed & & 0.0480 & 0.2079 & 0.8181 \\
\hline
\end{tabular}

Table 4: Final weight of criteria.

\begin{tabular}{|c|c|c|c|c|c|c|}
\hline \multirow{2}{*}{ Item } & \multirow{2}{*}{ Criterion } & \multicolumn{3}{|c|}{ Final weight of criteria } & \multirow{2}{*}{ 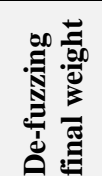 } & \multirow{2}{*}{ 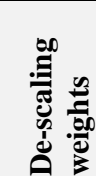 } \\
\hline & & 1 & 2 & 3 & & \\
\hline 1 & Access & 0.0145 & 0.4778 & 4.1278 & 1.5400 & 0.3373 \\
\hline 2 & General services & 0.0374 & 0.2681 & 4.2512 & 1.5189 & 0.3327 \\
\hline 3 & Communicational & 0.0149 & 0.1664 & 2.1190 & 0.7667 & 0.1679 \\
\hline 4 & Environmental & 0.0125 & 0.0877 & 2.1190 & 0.7397 & 0.1629 \\
\hline
\end{tabular}

Table 5: Definite reciprocal geometric average of triangular fuzzy numbers for subscales of access indicator.

\begin{tabular}{lllll}
\hline Item & Subscale & $\begin{array}{l}\text { First fuzzy } \\
\text { number }\end{array}$ & $\begin{array}{l}\text { Second fuzzy } \\
\text { number }\end{array}$ & $\begin{array}{l}\text { Third fuzzy } \\
\text { number }\end{array}$ \\
\hline 1 & Access to medical services & 0.3402 & 1.9722 & 4.3267 \\
2 & Access to round the clock services & 0.2513 & 1.0031 & 3.5569 \\
3 & Access to ambulance services & 0.2311 & 0.5055 & 3.2711 \\
Total rates Z & 0.8244 & 3.4808 & 11.1547 \\
$Z$ & 0.0896 & 0.2873 & 1.2130 \\
\hline
\end{tabular}

Table 6: Final weight of subscales of access indicator.

\begin{tabular}{|c|c|c|c|c|c|c|}
\hline \multirow{2}{*}{ Item } & \multirow{2}{*}{ Subscale } & \multicolumn{3}{|c|}{ Final weight of criteria } & \multirow{2}{*}{ 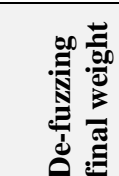 } & \multirow{2}{*}{ 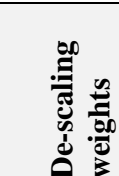 } \\
\hline & & 1 & 2 & 3 & & \\
\hline 1 & Access to medical services & 0.0307 & 0.5666 & 5.2482 & 1.9485 & 0.4003 \\
\hline 2 & Access to round the clock services & 0.0225 & 0.2882 & 4.3144 & 1.5417 & 0.3167 \\
\hline 3 & Access to ambulance services & 0.0207 & 0.1452 & 3.9677 & 1.3779 & 0.2830 \\
\hline
\end{tabular}

In this study, the variables of access with weight of 0.3373 and general services with weight of 03327 were identified as the most effective indicators on hospitals services quality. Among subscales of access to medical team with the weight of 0.4003 and access to round the clock services with the weight of 0.3167 were the most important sub- indicators effective on services quality. For the component of general services, the subscales of low cost with weight of 0.3623 and method of responding hospitals to the patients' needs with the weight of 0.3304 had a great impact on services quality. Relating to communicational component, subscales of personnel liability with the weight of 0.5836 and personnel correct contact with patients with the weight of $0.2773 \mathrm{had}$ a great impact on the services quality and for the environmental component, two subscales of facilities and equipment being up-to-date with the weight of 0.4140 and services quality with the weight of 0.3848 had the greatest impact on the services quality. Based on the results, this study show that access indicator with weight of 0.3370 has the highest significant among various dimensions of services quality. This dimension indicates access to hospital services provided by the hospital for the patients and the subscale of access to medical team, access to round the clock services and access to ambulance services are in the first to third rank. These results are highly consistent with the results of previous studies. The second important dimension of hospital services quality from patients attendants view is general services dimension with weight of 0.3327 . This dimension indicates non-treatment services provided by the hospital for the patients. Subscales of general services, low cost and method of responding the hospitals to the patients' needs, having insurance and less beds in rooms are in the first to fourth rank respectively. Hospital managers should have a special attention to these factors for improving quality and more satisfaction of patients. The third dimension of hospital services quality is the communication dimension with weight of 0.1670 which indicates the relation between services provider and user and includes subscales of personnel liability, correct contact of personnel with patients and personnel honesty which were located in the first to third rank respectively. It seems that in the patients' needs range, 
the communicational dimension is considered among the patients secondary needs and they prefer their health and treatment needs are met first and at present there are more important cases than hospital personnel behavior with them. Recognizing social and emotional needs of the patients by personnel and physicians is not only important in human respect, but it also may have a positive impact on their treatment process and will lead to their more loyalty to the hospital.

Table 7: Definite reciprocal geometric average of triangular fuzzy numbers for subcategories of general. services

\begin{tabular}{lllll}
\hline Item & Subscale & $\begin{array}{l}\text { First } \\
\text { fuzzy } \\
\text { number }\end{array}$ & $\begin{array}{l}\text { Second } \\
\text { fuzzy } \\
\text { number }\end{array}$ & $\begin{array}{l}\text { Third fuzzy } \\
\text { number }\end{array}$ \\
\hline 1 & Low cost & 0.2934 & 2.0460 & 4.5826 \\
2 & $\begin{array}{l}\text { Method of hospital responding to } \\
\text { patients' needs }\end{array}$ & 0.5774 & 1.5456 & 5.1962 \\
3 & Having insurance & 0.2510 & 0.7262 & 2.5900 \\
$4 \quad$ Less beds in each room & 0.2049 & 0.4355 & 1.8612 \\
Total rates Z & 1.3266 & 4.7532 & 14.2300 \\
$Z$ & 0.0703 & 0.2104 & 0.7538 \\
\hline
\end{tabular}

Table 8: Final weights of subscales of general services indicators.

\begin{tabular}{ll|lll|lll}
\hline Item & Subscale & \multicolumn{3}{|l|}{ Final weight criteria } & & \\
& & $\mathbf{1}$ & $\mathbf{2}$ & $\mathbf{3}$ & & \\
& & & & & & \\
& & 0.2060 & 0.4304 & 3.4543 & 1.3018 & 0.3623 \\
2 & Low cost & 0.0406 & 0.3252 & 3.9168 & 1.4275 & 0.3304 \\
3 & Method of hospital responding to & patients' needs & 0.0176 & 0.1528 & 1.9523 & 0.7076 & 0.1796 \\
4 & Having insurance & 0.0144 & 0.0916 & 1.4030 & 0.5030 & 1.1277 \\
\hline
\end{tabular}

Table 9: Definite reciprocal geometric average of triangular fuzzy numbers for communicational indicator subscales.

\begin{tabular}{lllll}
\hline Item & Subscale & $\begin{array}{l}\text { First fuzzy } \\
\text { number }\end{array}$ & $\begin{array}{l}\text { Second } \\
\text { fuzzy } \\
\text { number }\end{array}$ & $\begin{array}{l}\text { Third fuzzy } \\
\text { number }\end{array}$ \\
\hline 1 & $\begin{array}{l}\text { Personnel liability } \\
\text { Personnel correct }\end{array}$ & 0.3467 & 2.7885 & 8.5726 \\
2 & $\begin{array}{l}\text { contact with patients } \\
3\end{array}$ & 0.1682 & 0.8476 & 4.1602 \\
Total rates Z & 0.2311 & 0.4231 & 2.0801 \\
$Z$ & 0.7660 & 4.0592 & 14.8129 \\
\hline
\end{tabular}

Table 10: Final weight of subscales of communicational indicator.

\begin{tabular}{ll|llllll}
\hline Item & Subscale & \multicolumn{2}{|c|}{ Final weight of criteria } & De-fuzzing & De-scaling \\
& & $\mathbf{1}$ & $\mathbf{2}$ & $\mathbf{3}$ & weights \\
& & & & & & \\
\hline 1 & Personnel liability & 0.2403 & 0.6870 & 11.4908 & 4.0671 & 0.5836 \\
2 & $\begin{array}{l}\text { Personnel correct } \\
\text { contact with patients }\end{array}$ & 0.114 & 0.2088 & 5.5763 & 1.9322 & 0.2773 \\
3 & Personnel honesty & 0.0156 & 0.1042 & 2.7882 & 0.6993 & 0.1391 \\
\hline
\end{tabular}

Table 11: Definite reciprocal geometric average of triangular fuzzy numbers for subscales of environmental indicator.

\begin{tabular}{lllll}
\hline Item & Subscale & $\begin{array}{l}\text { First } \\
\text { fuzzy } \\
\text { number }\end{array}$ & $\begin{array}{l}\text { Second } \\
\text { fuzzy } \\
\text { number }\end{array}$ & $\begin{array}{l}\text { Third } \\
\text { fuzzy } \\
\text { number }\end{array}$ \\
\hline $1 \quad$ & $\begin{array}{l}\text { Facilities and } \\
\text { equipment being } \\
\text { updated }\end{array}$ & 0.3029 & 2.6113 & 4.3267 \\
& & & \\
\hline 2 & Food quality & 0.3333 & 1.0017 & 4.3267 \\
\hline $3 \quad$ Having parking & 0.2311 & 0.3823 & 2.2894 \\
\hline Total rates Z & 0.8673 & 3.9953 & 10.9429 \\
\hline Z reversed & 0.0914 & 0.2503 & 1.1530 \\
\hline
\end{tabular}


Table 12: Final weight of subscales of environmental indicators.

\begin{tabular}{ll|lll|ll}
\hline Item & Subscale & $\mathbf{5}$ & & \\
& & $\mathbf{1}$ & $\mathbf{2}$ & $\mathbf{3}$ & & \\
\hline 1 & $\begin{array}{l}\text { Facilities and } \\
\text { equipment being } \\
\text { updated }\end{array}$ & 0.0277 & 0.6526 & 4.9887 & 1.8900 & 0.4140 \\
2 & $\begin{array}{l}\text { Food quality } \\
3\end{array}$ & 0.0305 & 0.2507 & 4.9887 & 1.7566 & 0.3848 \\
Having parking & 0.211 & 0.0957 & 2.6397 & 0.9188 & 0.2013 \\
\hline
\end{tabular}

The fourth and least significant dimension from view of patients' attendants is environmental dimension with weight of 0.1620 which indicates environmental facilities and features which constitute the patients perception of services and includes subscales of facilities and equipment being up-to-date, food quality and having parking which are in the first to third priority. Giving importance to environmental dimension refers to factors like the rooms walls color, light, superficial attraction and hospital space, the cleanness status of rooms, hospitalization rooms and corridor ventilation status, modern and advanced equipment, patients files and records status, existence of stretcher and wheelchair, status of mattresses and refrigerators cleanness, ashcan, cleanness of lavatories, color and cleanness of personnel form and their appearance. Suitability of environmental conditions and facilities in the hospital not only causes patients and their attendants comfort and welfare, but also creates more suitable working conditions for the personnel which leads to providing better services to patients.

\section{AUTHOR'S CONTRIBUTION}

The manuscript was carried out, written, and approved in collaboration with all authors.

\section{ACKNOWLEDGEMENTS}

The authors extend their thanks and appreciation to the Islamic Azad University, Tehran, Iran to provide necessary facilities for this work.

\section{CONFLICT OF INTEREST}

No conflict of interest associated with this work

\section{REFERENCES}

1. Ahmadi Kohanali, R.Bengli A, Hosseinian Nodoshan S, et al. Prioritizing Factors Affecting the Quality of Hospital Services from Patients' Viewpoint Based on Fuzzy Analytical Hierarchy Process. J Med Inform 2017; (2)2: 2938. PMID: 26060745

2. Zarei A, Judge Tabataba'i S, Rahimi A, Rashidian A, Arab $\mathrm{M}$, et al. Assessing the quality of hospital services from a patient's point of view: a cross-sectional study in private hospitals in Tehran. Faculty of Paramedicine, Tehran University of Medical Sciences 2011: (4)5, 66-76.

https://doi.org/10.1016/j.sbspro.2016.11.082

3. Azizi Kh, Mazdaki A, Mirkazami Mod M, et al. Identification and prioritization of factors affecting patient satisfaction in medical centers: using multi-criteria decision making approach. Health Management 2016; 90-104. https://doi.org/10.1097/CIN.0000000000000576

4. Momeni M. New Operational Research Topics. Tehran: Tehran University Press 2011.

5. -Ross DS, Venkatesh R, et al. An Empirical Study of the factors influencing quality of healthcare and its effects on patient satisfaction. Int J Res Sci, Eng Techn 2015, 4(2), 5459. https://doi.org/10.15171/ijhpm.2014.65

6. Maharmeh M, Al-Hussami M, Darawad M, et al. Factors affecting the quality of care in cardiac outpatient departments: Patients' perspective. Scientific cooperations International workshops on medical topics 2014, 69-87.

7. Abuakar A. Factors affecting quality of laboratory services at infectious diseases hospital, Kano-Nigeria. Esiver.com. $2014 ; 1-110$

8. Liona D, Scort J, Michella R, et al. Satisfaction with counseling among black males in transition from the foster care system .www.elsiver.com. 2009; 1-11. https://doi.org/10.1016/j.childyouth.2008.07.008

9. Ayhan MB. A Fuzzy Ahp Approach For Supplier Selection Problem: A Case Study In a gear motor company. Int J Man Value Supp Chains 2013; 4, 11-24. https://doi.org/10.5121/ijmvsc.2013.4302 